\title{
Design and Analysis of Piston Rod Joint in Hydraulic Cylinder for Industrial Implements
}

\author{
M. Antony Maria Thomas Benny ${ }^{1}$, U.S. Chavan ${ }^{2}$ \\ I (Department of Mechanical Engineering, Vishwakarma Institute of Technology, Pune, India 411037) \\ ${ }^{2}$ (Department of Mechanical Engineering, Vishwakarma Institute of Technology, Pune, India 411037)
}

\begin{abstract}
As heavy engineering industries grows so is the implements and necessity for more powerful mechanisms to actuate theses implements. Hydraulic cylinders are one such actuators that generates linear translatory motion. Hydraulic cylinder force required for actuation depends on implement requirements and in heavier applications were output forces needed are higher, the internal components of the cylinder needs to withstand this higher loads and hence the design of hydraulic cylinder internal components gains importance. The cylinder rod and piston inside the cylinder are connected jointly either by bolt or nut. This paper concentrates more on these joints which experiences higher tensile or compressive loads during operations. There are instances during implement operation, when the cylinder reciprocates and reaches its extreme fully open position. When there is no more stroke available, the cylinder bottoms-up completely putting high tensile load on the rod and piston-rod joint which may even lead to failure of these joint and cylinder. In this analysis, a static structural analysis was performed on three synthesized cylinder rod-piston joints to investigate different loads that come on these joints and which is best suitable joint for industrial implements with high tensile and preload loads.
\end{abstract}

Keywords: Hydraulic cylinder joint, piston-rod joint, bolt preload analysis, cylinder bottom-up.

\section{Introduction}

A hydraulic cylinder is a complicated mechanical system that are used to provide linear force action and motion. Hydraulic cylinders are powered from externally pressurized hydraulic fluid. They are commonly used in equipment's and machinery, such as construction equipment like excavators, dozers and material handling equipment's like carry cranes, telescopic trucks etc. [1-2,6]

It consists mainly of cylinder barrel, piston and cylinder rod. The piston that is placed within the barrel is connected to the cylinder rod either by bolt or nut. The piston reciprocates producing linear force with compression and tension forces perfectly align in the rod's axial direction. In the majority of applications, where bolts and nuts are used, it is the clamping force provided by torqueing of the bolt/nut plays major role which is crucial factor in determining the structural integrity of the joint [7]. The wrong tightening is one of the most frequent causes of ductile rupture and a frequent cause of fatigue failure [9].

The aim of this study is to analysis one such implement mechanism to find out the maximum tensile load that comes on the piston-rod joint and required preload for no joint separation. The calculated tensile and pretension loads are applied on synthesized piston-rod concepts that are considered for analysis in order to find out the most suitable joint which would withstand the worst case hydraulic cylinder bottoming-up created by the implement mechanism.

\section{Literature Review}

Numerous studies have been carried out related to hydraulic cylinder failures based on loads, pretensioning loads under static loading conditions and fatigue loading cycles.

Sh. Molaei and R. Alizadeh [1] carried out failure analysis of the fractured connecting bolts of a filter press. They investigated failure causes of sixteen connecting bolts on rod and piston of a filter and found probably low tightening torques were used for the assembly and reason for failure of the joints. G. Nicoletto and T. Marin [2] conducted unexpected in-service failure of a heavy-duty hydraulic cylinder. The combined use of fracture mechanics concepts and finite element method demonstrated that part failure was due to the specific weld joint solution between cylinder and end-cap and the fatigue life predictions correlated with the estimated service life before crack detection. Saman Fernando [3] analyzed two mechanisms of vibration loosening bolts and identified critical parameters in preventing loosening of bolt joints. Finally, based on results it was found at least, preload of 65 percent of fastener proof load should prevent loosening under vibration at all vibration environments.

John D. Reiff [4] developed procedures for calculating the coefficient of friction of bolt/nut assemblies and for calculating torque specifications which includes the cases where the fasteners have prevailing torque. The new equations developed basically resulted in 15 percent enhancement in the accurateness of torque 
specification calculations. S.M.O. Tavaresa [5] carried out failure analysis of hydraulic cylinder rod and shows that rupture of the rod of the hydraulic cylinder was due to fatigue failure resulting from excessive stress concentration factor of shoulder fillet of the rod. The paper discusses this case as (i) a conventional Soderberg approach, and (ii) a DIN 743 analysis. With Soderberg criterion a safety factor bigger than 1.2 is recommended, whereas DIN 743 approach allows the use of 1.2. ThankGod E. Boye [6] carried out design and analysis of hydraulic cylinders by forming combined equations of analytical and finite element analysis methodology. The longitudinal stresses, bursting pressures, piston rod and piston diameter, barbell thickness were calculated and analyzed. Jean-Michel Monville [7] investigated that incorrect tightening of bolt joint is one of most common reasons of ductile breakage and also reason for most of frequent cause of fatigue failures. Paper focuses on 'hydraulic tensioner' to show how tightening load can be found based on applied pretension load and to suggest a new way for optimization of bolt torqueing procedures. Henri Walaszek [8] studied that ultrasonic method of bolt tightening gives information of stress generated in bolts due to preload. The pre-load provides right measuring of tension generated on bolt joint, independent of manufacturing tolerances. It uses 'bi-wave method' using electromagnetically coupled transducers (EMAT) and data of applied stress on bolts with 5\% of uncertainty. W. Eccles [9] presented a new approach to check tightness of bolted connection. This shows a new method to find the torque required to rotate and tighten the joint and then instantaneously doing in opposite direction which allows load available on bolted connection to be ascertained correctly. Paul Copeland [10] investigated on 'Dynamic Tightening of a Bolted Joint', a novel bolt joint model was established which allows 'dynamic tightening' of bolt into threaded holes by physical model behaving non-linearly with helical threaded pattern. Evaluation of clamping load with the original joint exhibited 0.15 percentage variance with the original and FEA bolts. Average plastic deformation on joint bearing surface correlated with original joint.

\section{Closer Review}

From the literature review, lot of works were carried out of cylinder piston rod bolts torqueing produces and reason for failures. But there are no much work carried out on analyzing different types of cylinder rod-piston joint or load cases creating maximum tensile load on theses joints. In this paper, for such high tensile load applications what could be a better option of either connecting hydraulic cylinder rod-piston using bolt or nut or any other type of joints is analyzed in depth with experimental validations.

\section{Objective}

When a hydraulic cylinder reaches its fully opened position at bottoming up condition

1. The maximum tensile load from implement mechanism and

2. Synthesis of concepts for hydraulic cylinder rod-piston joint and maximum preload for no joint separation due to maximum tensile load from the implements.

3. FEA analysis of the concepts for tensile loads and pre tension loads.

4. Experimental validation of selected concepts based on FEA analysis and find out which is best cylinder rodpiston joint for hydraulic cylinder used in heavy applications.

\section{Geometry And Material Properties}

\section{Assumptions}

For design and analysis of piston-rod joints common standard hydraulic cylinder with following specifications are considered,

1. Cylinder Internal Bore diameter $-100.08 \mathrm{~mm}$; 2. Rod diameter $-49.96 \mathrm{~mm}$;

3. System Pressure - 1800 psi; 4. Material - EN 19 alloy steel.

\section{Load Analysis on Cylinders}

Loads operation based on implement mechanism analysis,

a) Total tensile load (Vertical Load \& Hydraulic cylinder force) and from load analysis the total maximum tensile load was calculated to be $400 \mathrm{kN}$, with design factor of safety -2 [15]

b) Bolt/nut pretension - The bolt pretension calculated [11] for no joint separation was $300 \mathrm{kN}$ (for M30x3.5x70, 10.9 grade bolt and M30x3.5x26.5, class 10 nut).

\section{Concept Generation}

Fig.1 shows concepts of rod and piston joint in hydraulic cylinders that were synthesized for design \& analysis, 1. Case I - Piston and rod assembled using threaded nut, 2. Case II - Piston and rod assembled using threaded bolts, 3. Case III - Piston and rod assembled using radial pins. 


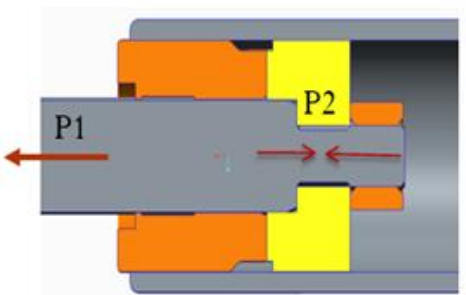

Case - I

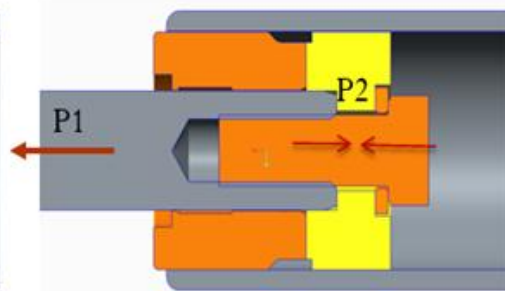

Case - II

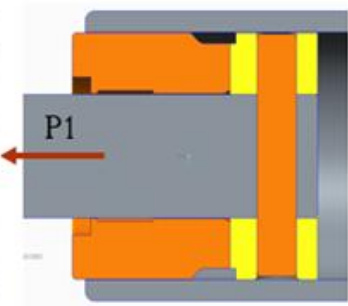

Case - III

\section{Geometry}

Fig. 1. Concepts

Fig. 2 shows standard cylinder details: Cylinder Bore diameter: $100 \mathrm{~mm}$; 2. Rod diameter: 50 mm Material: EN 19; Yield Strength $=690 \mathrm{Mpa}$; UTS $=814 \mathrm{Mpa}$; Poisson's ratio $=0.3 ; \mathrm{E}=210 \mathrm{GPA}$

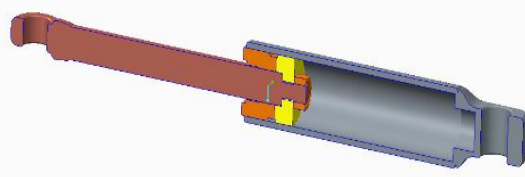

Fig. 2. Geometry

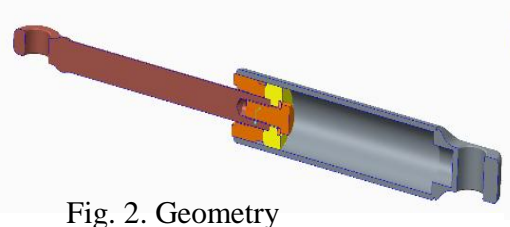

IV. Finite Element Analysis

The FEA analysis was carried out for the hydraulic cylinder joint geometry for all three piston-rod concepts and was analyzed under static structural loading conditions. Following are the load cases that were considered for the analysis,

1. Maximum tensile Load of $400 \mathrm{kN}$ on cylinder rod (working load $=200 \mathrm{kN}$, design factor - 2)

2. Bolt/nut pretension load of $300 \mathrm{kN}$ on cylinder rod and piston joint.

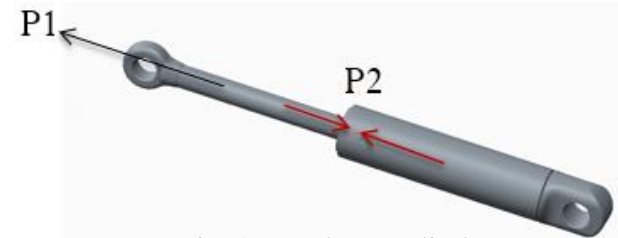

Fig. 2. Loads on cylinder

\begin{tabular}{|l|l|l|}
\hline S. No. & Load & Values \\
\hline 1 & Pretension & $300 \mathrm{kN}$ \\
\hline 2 & Total Tensile force & $400 \mathrm{kN}$ \\
\hline
\end{tabular}

Fig. 4. Loads on cylinder

FEA Modelling and Boundary conditions

Finite element model details. ANSYS 17.0 version was used for finite element analysis.

1. Meshing element type is 4 node quad shell 181.

2. For bolt/nut mesh size $1 \mathrm{~mm}$; for rod, piston mesh size $3 \mathrm{~mm}$; Barrel, cylinder cup mesh size is $8 \mathrm{~mm}$.

3. Node population count 1431768; Element population count 985556

4. Total Tensile load $(\mathrm{P} 1)=400 \mathrm{kN}$ applied on rod end of the cylinder; Pretension $(\mathrm{P} 2)=300 \mathrm{kN}$.

5 . Load behavior is taken as rigid which resembles the practical case.

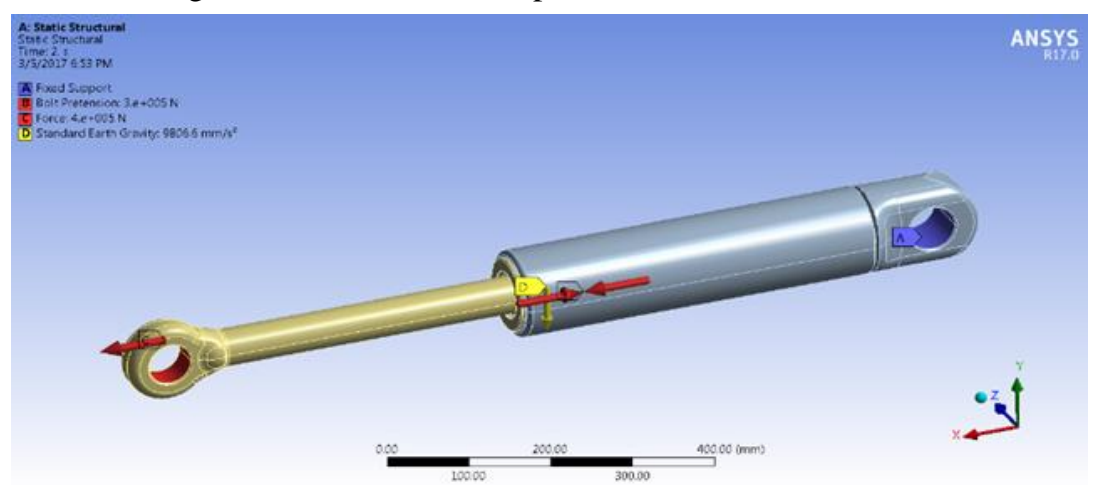

Fig. 5. FEA geometry

\section{Boundary conditions:}

1. Cylinder barrel end was considered are fixed.

2. Contacts between barrel \& cup, bolt/nut thread and cylinder rod threads were considered as bonded.

3. All other contacts were considered as frictional with co-efficient of friction as 0.2 


\section{Concpet-1}

Fig. 1 case I, shows concept 1 geometry were the cylinder rod and piston is connected using M30x3.5x26 nut of class 10. Bolt pretension was given in the shank region of cylinder rod. Figure 5 (Nut, rod full section, rod cross section) shows equivalent stress distribution of concept 1 under $400 \mathrm{kN}$ tensile load and $300 \mathrm{kN}$ pretension load. Maximum variation between calculated \& FEA values are 3\% approximately.
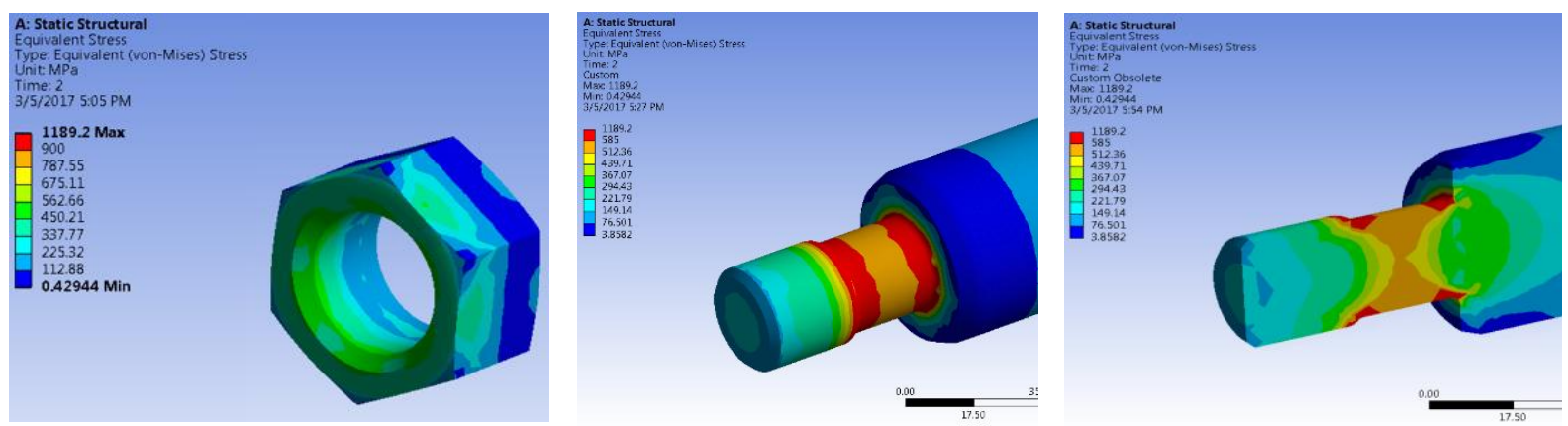

Fig. 6. Concept1 - Maximum Equivalent Stress Distribution

\section{Concpet-2}

In concept 2 geometry, the cylinder rod and piston is connected using M30x3.5x70 bolt of Grade 10.9. Bolt pretension was given in the shank region of bolt. Figure 6 (bolt, rod full section, rod cross section) shows equivalent stress distribution of concept 1 under $400 \mathrm{kN}$ tensile load and $300 \mathrm{kN}$ pretension load. Maximum variation between calculated \& FEA values are $4 \%$ approximately.
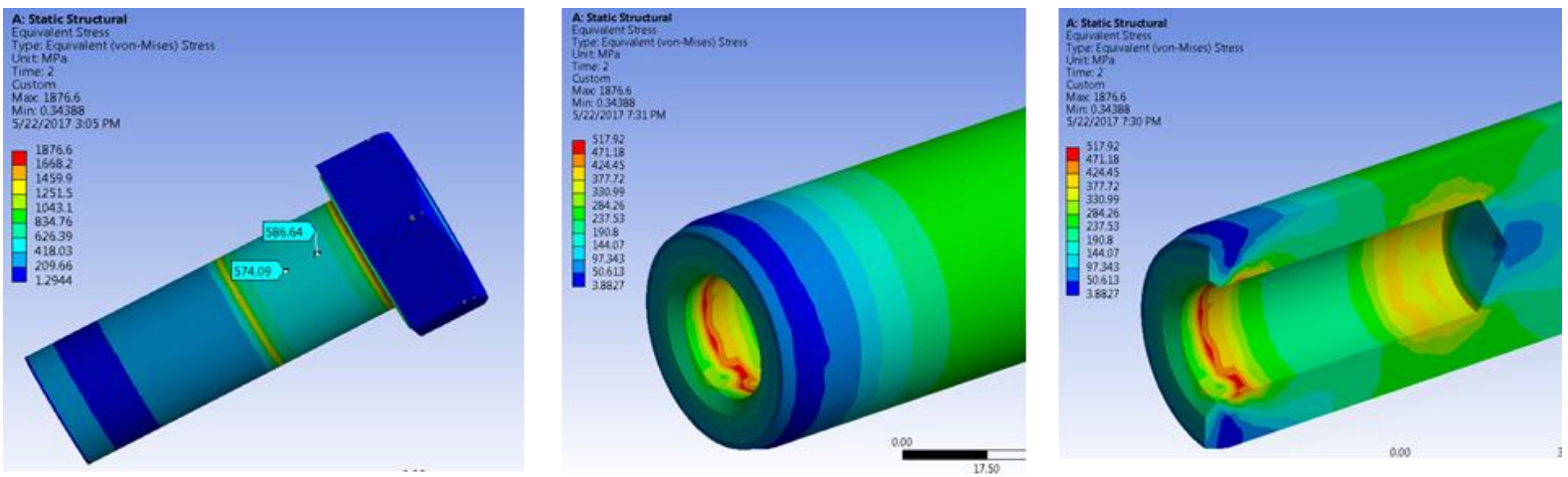

Fig. 7. Concept2 - Maximum Equivalent Stress Distribution

\section{Concpet-3}

In concept3 geometry, the cylinder rod and piston is connected using radial pin of EN 19. A interference fit between rod and pin was maintained. Figure 2 (full section) Figure 2 (cross section) shows equivalent stress distribution of concept1 under $400 \mathrm{kN}$ tensile load and $300 \mathrm{kN}$ pretension load. Maximum variation between calculated \& FEA values are $17.23 \%$ approximately.
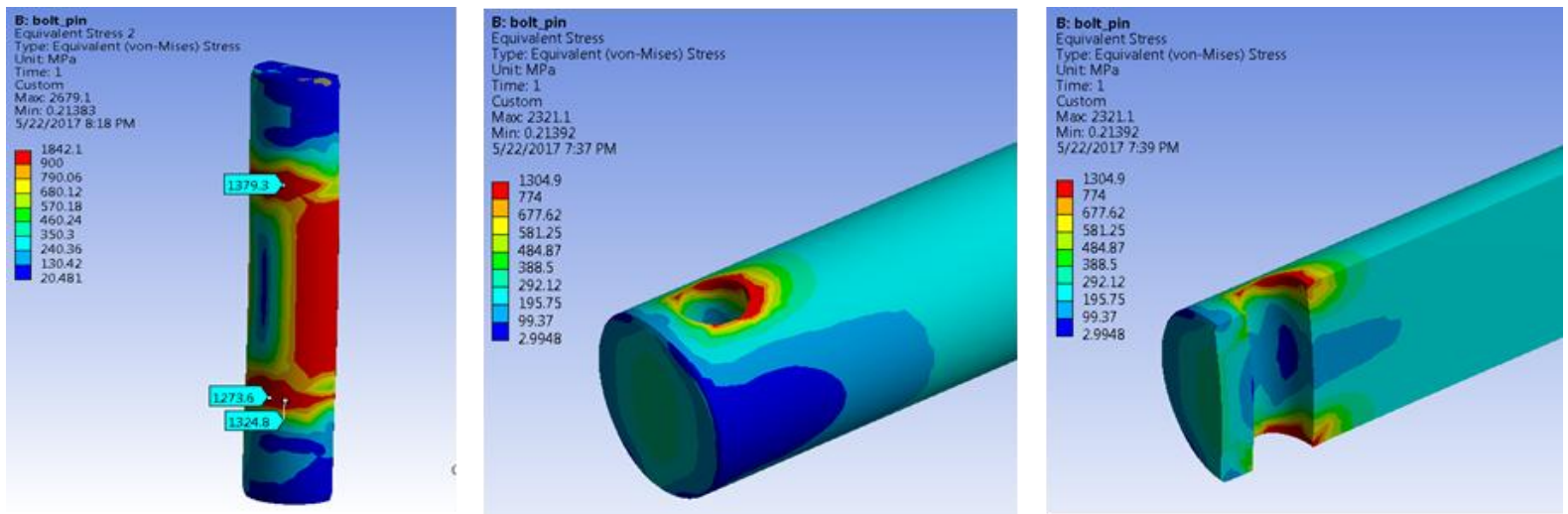

Fig. 8. Concept3 - Maximum Equivalent Stress Distribution 


\section{Results \& Discussion}

1. It was found that Case II: Piston rod Bolt joint met the design acceptance criteria and case I and Case III piston rod joints didn't met the design acceptance criteria of EN 19 yield strength.

2 . Based on von-misses equivalent stresses and maximum principal stresses results, concept-1 and concept-2 type piston-rod joints are selected for experimental validations.

Tensile test \& chemical composition test:

\section{Experimental Validation}

Fig.8. shows specimen preparation as per ASTM E8/E8M [14]. Chemical analysis carried out by OES method. UTS - 915 N/mm2; Yield Strength - 774 N/mm2

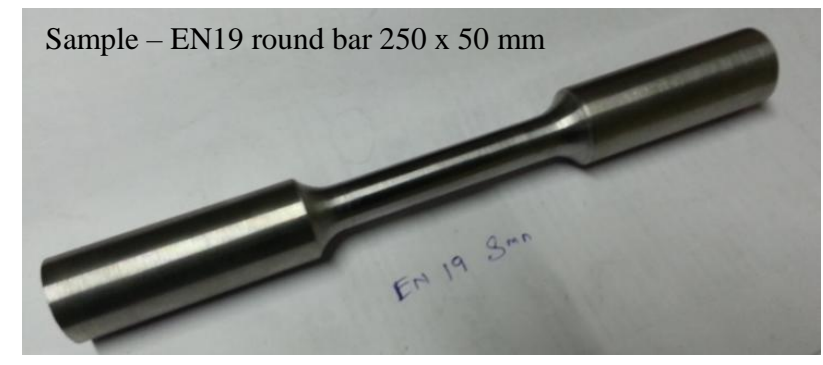

Fig. 9. Test Specimen

\begin{tabular}{|} 
1. Chemical analysis (\%Wt.) by OES method(Test metluud- I88811-1998(RA2006)) \\
\begin{tabular}{|c|c|c|c|}
\hline Sr. No. & Parameter & Specifications & Observed values \\
\hline 1 & $\mathrm{C}$ & $0.35 \sim 0.45$ & 0.41 \\
\hline 2 & $\mathrm{Mn}$ & $0.50 \sim 0.80$ & 0.79 \\
\hline 3 & $\mathrm{Si}$ & $0.10 \sim 0.35$ & 0.27 \\
\hline 4 & $\mathrm{~S}$ & $0.050 \mathrm{Max}$ & 0.028 \\
\hline 5 & $\mathrm{P}$ & $0.050 \mathrm{Max}$ & 0.015 \\
\hline 6 & $\mathrm{Cr}$ & $0.90 \sim 1.50$ & 0.91 \\
\hline 7 & $\mathrm{Mo}$ & $0.20 \sim 0.40$ & 0.20 \\
\hline
\end{tabular}
\end{tabular}

Fig. 10. EN 19 Chemical Test Results

\section{Proto Testing: Case I-Test Setup in UTM}

Fig. 9 shows mounting from the bottom of UTM machine. Circular disc made of EN 19 material 35 mm thick. Bolted using two M12 bolts to bottom.
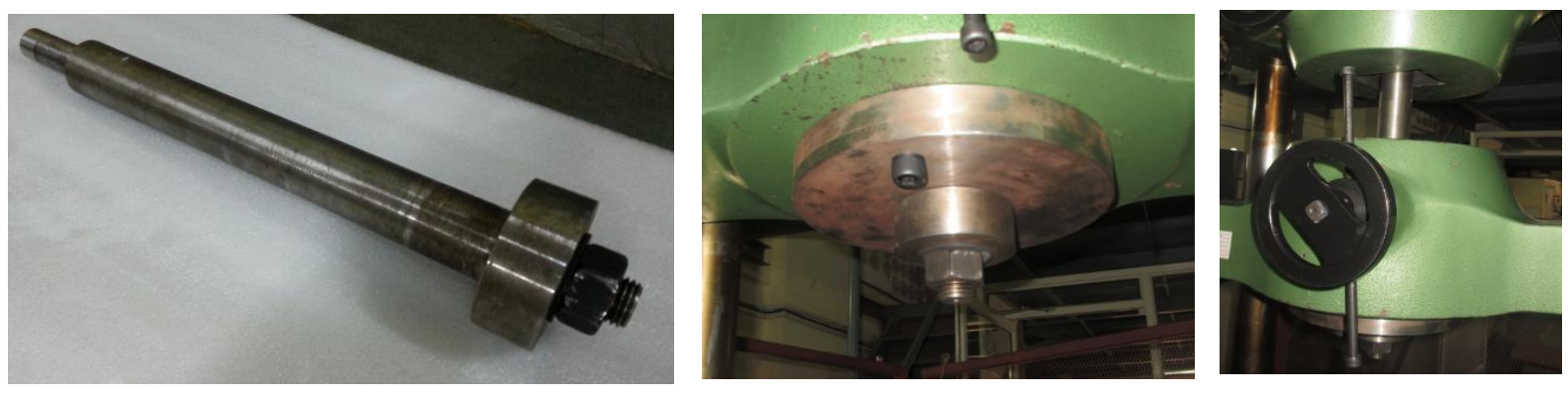

Fig. 11. Case I-Test setup in UTM

\subsection{Tensile Pull Test Observations:}

Fig.10, Fig.11 - The concept-1 tensile pull test of piston rod nut joint was tested on the 60T UTM machine at static loadings. Local yielding started at $400 \mathrm{kN}$ which eventually yielded to breakage/failure of the cylinder rod joint at $468 \mathrm{kN}$. Failure of the rod at the threaded region was observed at perpendicular plane to load acting direction.

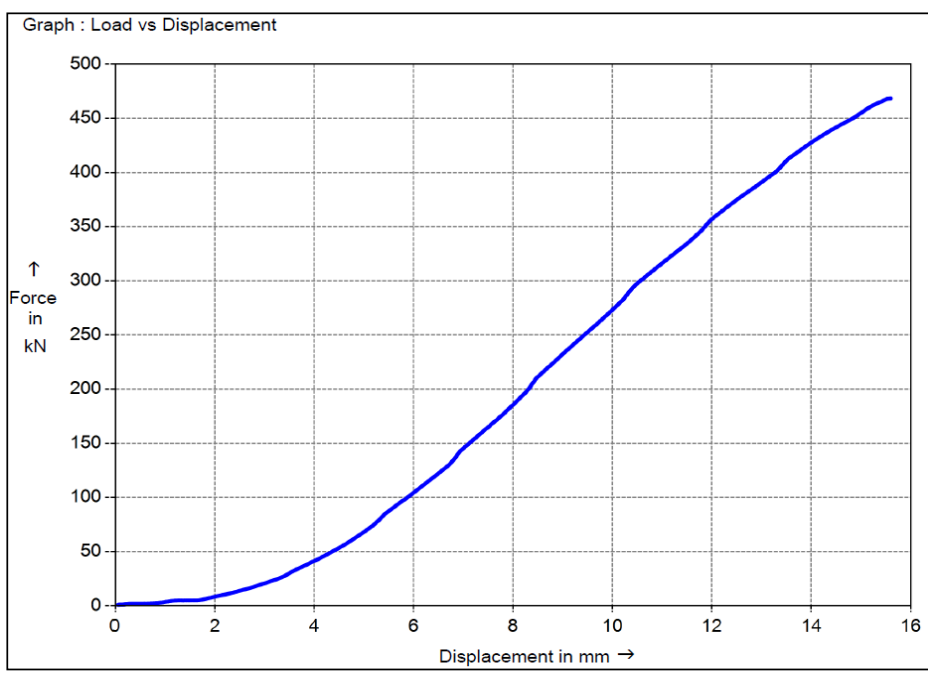

Fig. 12. UTM Test Result Concept1 - Load Vs Displacement Graph
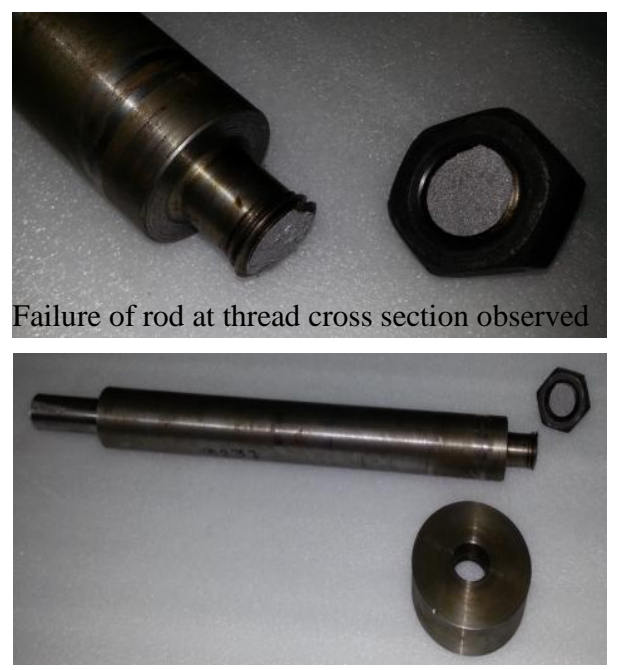

Fig. 13. Test Result Concep1 - After Testing 


\section{Proto Build: Case II - Test Setup in UTM}

Fig. 12. Shows mounting of circular plate from the middle chuck bottom of 60T UTM machine. Circular disc made of EN 19 material with $35 \mathrm{~mm}$ thick. It is bolted using two M12 bolts to bottom of middle chuck of UTM machine.
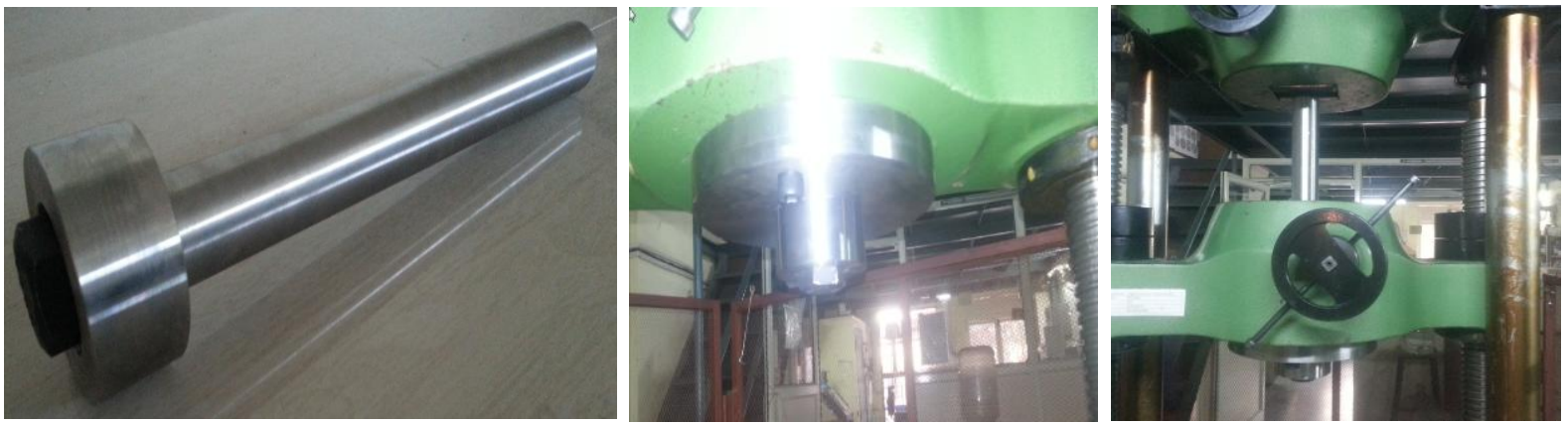

Fig. 14. Case II-Test setup in

\subsection{Tensile Pull Test Observations:}

The concept-2 tensile pull test of piston-rod bolt joint was tested on the 60T UTM at static loadings. The tensile pull load was given till $480 \mathrm{kN}$. No failure of the piston rod joint observed Fig. 16.

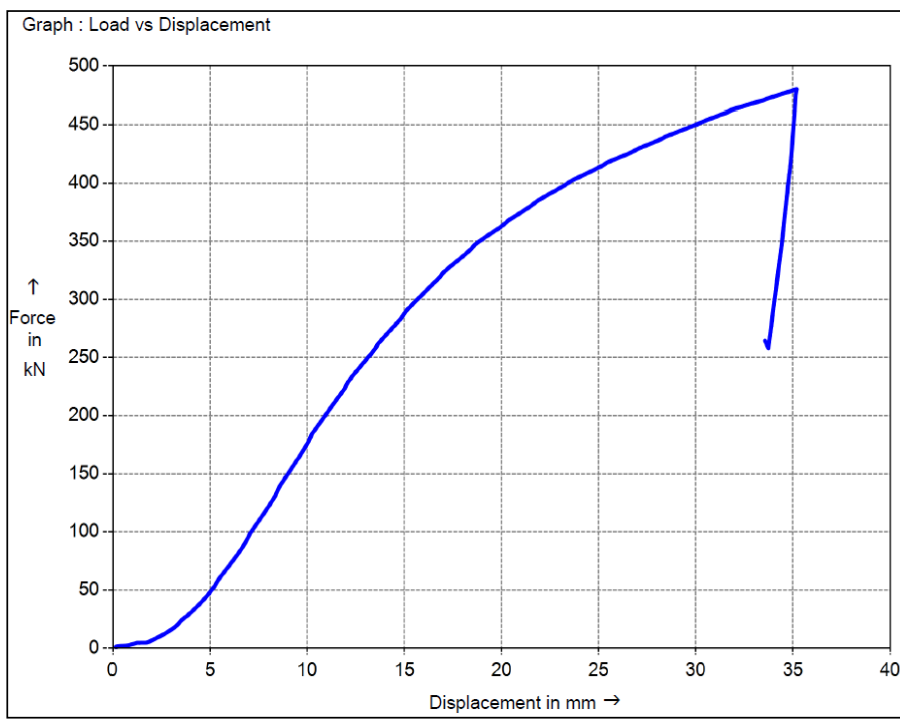

Fig. 16. UTM Test Result Concept2 - Load Vs Displacement

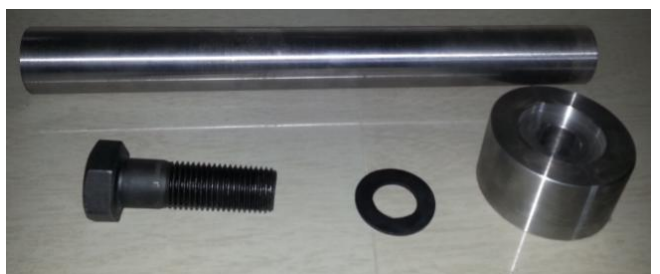

Fig. 15. Components before assembly

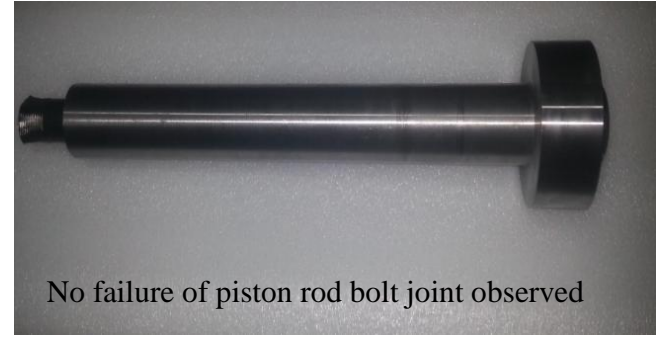

Fig. 17. Test Result Concep2 - After Testing

\section{Conclusion}

The implement mechanism was analyzed and total tensile load on cylinder rod including hydraulic cylinder force was $400 \mathrm{kN}$ (with factor of safety of 2). Based on concept-1 \& concept-2 geometry analysis the joint pretension load required based on total tensile load was calculated to be $300 \mathrm{kN}$.

In concept-1 piston-rod nut joint, maximum von misses equivalent stress variation on nut between calculated $(733.21 \mathrm{Mpa})$ \& FEA analysis $(743.09 \mathrm{Mpa})$ were around $1.33 \%$ approximately and for cylinder rod shank maximum von misses equivalent stress variation between calculated (1270.42 Mpa) \& FEA analysis (1329.2 Mpa) were around $4.43 \%$ approximately.

In case of concept-2 piston-rod bolt joint, for bolt maximum von misses equivalent stress variation between calculated $(569.31 \mathrm{Mpa})$ \& FEA analysis (584.24) were around $2.56 \%$ approximately and for cylinder rod maximum von misses equivalent stress variation between calculated (496.45 Mpa) \& FEA analysis (517.92 Mpa) were around $4.96 \%$ approximately.

Concept I and Concept II joints were selected for experimental validation based of FEA analysis results. Both the joints were torqued to $1900 \mathrm{~N}-\mathrm{m}$ based on pretension load calculation.

Experimental validation for concept I and concept II piston-rod joint were completed with a Universal Tensile Machine (60T) simulating the total tensile load $(400 \mathrm{kN})$. During tensile pull testing it was observed that piston-rod nut joint (concept-1) had a local yielding at $400 \mathrm{kN}$ and completely got ripped off at $468 \mathrm{kN}$ leading to brittle fracture of the joint at threaded region. In case of piston-rod bolt joint (concept-2) even though the load 
was raised up to $480 \mathrm{kN}$ no failure was observed and the piston-rod joint remained undamaged with no separation.

Also it is observed that the pretension in concept-2 type joint happens on the shank of 10.9 grade M30 bolt were as in of concept-1 type joint the pretension happens on the cylinder rod shank of EN 19 material which yielded the joint locally.

To conclude, the tensile stresses generated during static testing of Case II piston rod bolt joint with 'M30x3.5x100, 10.9 grade bolt' was within the yield limit of EN 19 material and meets the design acceptance criteria up to $480 \mathrm{kN}$ tensile load.

\section{Acknowledgement}

I am highly indebted to Prof. Dr. Umesh Chavan Mechanical department, VIT for his guidance and constant supervision throughout the project execution till completion. I would like to express my special gratitude towards my parents \& sisters for their kind support and encouragement which motivated me to complete my project work. I would like to express my thanks to all my colleagues and persons who has supported me directly and indirectly throughout the execution.

\section{References}

[1] Sh. Molaei, R. Alizadeh, M. Attarian, Y. Jaferian, "A failure analysis study on the fractured connecting bolts of a filter press", Published by - Elsevier Journal, volume 4, October 2015, pp 26-38.

[2] G. Nicoletto and T. Marin, "Fatigue Optimization of a Heavy-duty Hydraulic Cylinder" Published by - Elsevier Journal, volume 18, issue 3, April 2011 2015, pp 1030-1036.

[3] Dr Saman Fernando, "Mechanisms and prevention of vibration loosening in bolted joints", Published by - Australian Journal of Mechanical Engineering, September 2015, vol. no. 2, issue 2.

[4] John D. Reiff, "A Procedure for Calculation of Torque Specifications for Bolted Joints with Prevailing Torque", Published by Journal of ASTM International, March 2005, vol. 2, issue no. 3.

[5] S.M.O. Tavares, N. Viriato, M. Vaz, P.M.S.T. de Castro, "A failure analysis of the rod of a hydraulic cylinder", Published by Elsevier Journal, volume 1, February 2016, pp 173-180.

[6] ThankGod E. Boye, Adeyemi, I. Olabisi,Eyere E. Emagbetere, "Design and Finite Element Analysis of Double - Acting, Double Ends Hydraulic Cylinder for Industrial Automation Application”, Published by - American Journal of Engineering Research (AJER) 2017, volume 6, issue 3, pp 131-138.

[7] Jean-Michel Monville , "Optimal tightening process of bolted joints", Published by International Journal for Simulation and Multidisciplinary Design Optimization (IJSMDO), volume 7, article no. A4, September 2016.

[8] Henri Walaszek, Patrick Bouteille, "Application of ultrasonic measurements to stress assessment on already tightened bolts", Published by Scientific.net, Tans Tech Publications, volume 524-525, September 2006, pp 459-64.

[9] W. Eccles, "A new approach to the checking of the tightness of bolted connections", Published by - Fastener plus Fixing Technology Magazine, Issue 15, October - December 2014.

[10] Paul Copeland, Michael Oliver, "The Dynamic Tightening of a Bolted Joint", 2006 international ANSYS conference, May 2-4, 2006.

[11] Robert L. Norton, "Machine Design, An integrated Approach", Published by - Pearson -second edition, Twelfth impression 2013.

[12] Joseph E Shigley, "Mechanical Engineering Design", Published by - Tata McGraw Hill -eighth edition, special Indian edition 2008.

[13] ASTM E8/E8M-15a, "Standard Test Methods for Tension Testing of Metallic Materials", Published by - American National Standard.

[14] ASME B30.1-2015, “Jacks, Industrial Rollers, Air Casters and Hydraulic Gantries" Published by - American National Standard. 